DOI: 10.20472/IAC.2017.034.045

KARUNANIDHI REDDY

Durban University of Technology, South Africa, South Africa

\title{
SOCIAL JUSTICE, THE FOOD PRODUCT CONSUMER AND NON-COMMUNICABLE DISEASES: IMPLICATIONS OF CONSUMER PROTECTION LEGISLATION FOR THE FOOD INDUSTRY IN SOUTH AFRICA
}

\begin{abstract}
:
Many health problems are related to food and diet patterns. Socio-economic development in South Africa has meant a change in diet patterns, with poorer communities moving away from traditional foods to convenience and processed foods. These foods have been associated with obesity and could greatly increase the risk of developing food-related non-communicable diseases, including diabetes, high blood pressure and heart disease. In addition, apartheid resulted in inequality among consumers in terms of education levels, literacy and understanding of the language used in labelling and product information, as well as in terms of access to good quality commodities that are arguably healthier. It also resulted in inequality in terms of knowledge of consumer rights and the ability to enforce them, and a lack of information and knowledge as to food related health challenges.

Particular sectors in the food industry have been less concerned about the consumer health risks associated with their products or communicating such information to their consumers. Hence, recently there have been initiatives by government to protect consumers against food related non communicable diseases by proposing legislation to curb consumption of specific food products. The proposed "sugar tax" on sugar sweetened beverages is one example.

The Consumer Protection Act (CPA), passed in 2008, aims at protection of consumers by prohibiting or regulating a range of marketing and business practices and affording the consumer a range of legal rights and remedies. This paper investigates the implications of the CPA and related legislation, for the food industry and consumers of food products. The approach adopted for this paper is a descriptive critique engaging in a review of related literature, and pertinent legislation, particularly the CPA. It is envisaged that this paper will highlight the implications of the CPA in terms of the rights of consumers and the concomitant obligations of suppliers of food products, to re-examine the health risks related to their products, food labelling, disclosure of information particularly about associated health risks, and consumer education about products, in plain and understandable language. It will also identify possible gaps in the law requiring specific regulation.
\end{abstract}

\section{Keywords:}

Consumer; consumer protection; non-communicable diseases; food products; food industry ; social justice; South Africa

JEL Classification: K29, L66 